\title{
Trends for Methane Oxidation at Solid Oxide Fuel Cell Conditions
}

Kleis, Jesper; Jones, Glenn; Abild-Pedersen, Frank; Tripkovic, Vladimir; Bligaard, Thomas; Rossmeisl, Jan

Published in:

Journal of The Electrochemical Society

Link to article, DOI:

10.1149/1.3230622

Publication date:

2009

Document Version

Publisher's PDF, also known as Version of record

Link back to DTU Orbit

Citation (APA):

Kleis, J., Jones, G., Abild-Pedersen, F., Tripkovic, V., Bligaard, T., \& Rossmeisl, J. (2009). Trends for Methane Oxidation at Solid Oxide Fuel Cell Conditions. Journal of The Electrochemical Society, 156(12), B1447-B1456. https://doi.org/10.1149/1.3230622

\section{General rights}

Copyright and moral rights for the publications made accessible in the public portal are retained by the authors and/or other copyright owners and it is a condition of accessing publications that users recognise and abide by the legal requirements associated with these rights.

- Users may download and print one copy of any publication from the public portal for the purpose of private study or research.

- You may not further distribute the material or use it for any profit-making activity or commercial gain

- You may freely distribute the URL identifying the publication in the public portal 


\title{
Trends for Methane Oxidation at Solid Oxide Fuel Cell Conditions
}

\author{
Jesper Kleis, ${ }^{\text {a,z }}$ Glenn Jones, ${ }^{\text {a }}$ Frank Abild-Pedersen,,${ }^{\text {a,b }}$ Vladimir Tripkovic, ${ }^{a}$ \\ Thomas Bligaard, ${ }^{\mathrm{a}, \mathrm{c}}$ and Jan Rossmeisl ${ }^{\mathrm{a}}$ \\ ${ }^{a}$ Center for Atomic-scale Materials Design, Department of Physics, Technical University of Denmark, \\ DK-2800 Kgs. Lyngby, Denmark \\ ${ }^{b}$ Computational Materials Design ApS, DK-2800 Kgs. Lyngby, Denmark \\ ${ }^{c}$ Materials Science Division, Lawrence Berkeley National Laboratory, Berkeley, California 94720, USA
}

\begin{abstract}
First-principles calculations are used to predict a plausible reaction pathway for the methane oxidation reaction. In turn, this pathway is used to obtain trends in methane oxidation activity at solid oxide fuel cell (SOFC) anode materials. Reaction energetics and barriers for the elementary reaction steps on both the close-packed $\mathrm{Ni}\{111\}$ and stepped $\mathrm{Ni}\{211\}$ surfaces are presented Quantum-mechanical calculations augmented with thermodynamic corrections allow appropriate treatment of the elevated temperatures in SOFCs. Linear scaling relationships are used to extrapolate the results from the Ni surfaces to other metals of interest This allows the reactivity over the different metals to be understood in terms of two reactivity descriptors, namely, the carbon and oxygen adsorption energies. By combining a simple free-energy analysis with microkinetic modeling, activity landscapes of anode materials can be obtained in terms of these two descriptors. This not only simplifies the view of the oxidation process but it also gives insight into which reaction pathways are likely to be dominant over the different transition-metal anode materials. Most importantly, it reveals the properties the ideal alloy catalyst should possess.
\end{abstract}

(C) 2009 The Electrochemical Society. [DOI: 10.1149/1.3230622] All rights reserved.

Manuscript submitted April 29, 2009; revised manuscript received July 6, 2009. Published October 22, 2009.

Solid oxide fuel cells (SOFCs) are promising candidates for future power plants. Up to $60 \%$ of the chemical energy of fuels can be converted directly into electricity in SOFCs, and with additional utilization of the generated heat an overall efficiency of $75 \%$ can be reached. In comparison, the maximal efficiency of a modern coalbased power plant is approximately $45 \%{ }^{1}$

The SOFCs are operated at high temperatures $\left(\sim 800\right.$ to $\left.1000^{\circ} \mathrm{C}\right)$ for the solid oxide membrane to reach adequately favorable ionic transport properties, and the high temperature makes the SOFCs flexible with respect to both the catalytic material and the types of fuel they can utilize. The high temperature, however, makes the catalysts more fragile and prone to degradation, and it requires timeconsuming preheating to reach the working conditions. Thus, an important challenge is to lower the temperature at which the cell operates, and a significant effort is being made on developing improved solid oxide electrolytes. At lower operating temperatures, however, not only the ionic transport properties deteriorate but also the electrocatalytic reactions at the electrodes could become ratelimiting and must therefore also be optimized. To achieve this it becomes important to understand the elementary reaction mechanisms and determine the trends in both cathode and anode reaction rates over different catalyst materials. It is particularly important to establish highly active anode materials for lower temperature SOFCs because some flexibility is desirable to address the additional problems for the electrocatalysts as sulfur poisoning ${ }^{2-4}$ and coking, ${ }^{5-7}$ which a good catalyst must also overcome.

The hydrogen oxidation activity trend under SOFC conditions has already been successfully described by one of us ${ }^{8}$ and independently by Mukherjee and Linic. ${ }^{9}$ Inspired by those studies, in which the oxygen spillover pathway provided the foundation for a successful description of the activity trends, we proceed along a similar path to describe the SOFC activity for the methane oxidation process.

In an oxygen spillover picture, such as suggested in Ref. 8 and 9, the electrocatalytic methane oxidation process is essentially transformed into a surface methane reforming process where methane is dehydrogenated and combined with oxygen to form water and carbon dioxide. This process can follow various possible pathways. We will focus on two pathways: The route by which methane is fully dehydrogenated to $\mathrm{C}^{*}+4 \mathrm{H}^{*}$ followed by direct oxidation of $\mathrm{C}^{*}$ to $\mathrm{CO}^{*}$, and second, the route where dehydrogenation ends at $\mathrm{CH}^{*}$

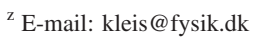

$+3 \mathrm{H}^{*}$ and $\mathrm{CO}^{*}$ formation follows via two steps: $\mathrm{CH}^{*}+\mathrm{O}^{*}$ $\rightarrow \mathrm{HCO}^{*} \rightarrow \mathrm{H}^{*}+\mathrm{CO}^{*}$. The second pathway proves to be hugely favorable on close-packed terraces as previously noted. ${ }^{10,11}$

In this paper the elementary steps in the pathways over $\mathrm{Ni}$ are mapped out by applying density functional theory (DFT) calculations to determine reaction energies and barriers. Ni is chosen, as $\mathrm{Ni}$-YSZ (YSZ denotes yttria-stabilized zirconia) cermet is the most widely used SOFC anode material. ${ }^{1}$ The zero-temperature DFT energies are augmented by thermodynamic corrections to account for the elevated temperatures in SOFCs.

To allow a trend study, in which the screening of a large number of different materials is possible, the reaction energy diagram over $\mathrm{Ni}$ is extended by using scaling relations for intermediates ${ }^{12}$ and barriers. ${ }^{13-15}$ The scaling relations allow us to describe the energetics of all the reaction intermediates in terms of the carbon and oxygen adsorption energies only. On this basis we make a simple kinetic analysis, which leads to the construction of a map of the most active elemental metal catalysts and gives insight into the rate-determining steps (RDSs) for each metal.

Understanding the chemical reactivity in terms of $\mathrm{C}$ and $\mathrm{O}$ adsorption energetics over metals points to the key fundamental properties for optimal anode materials. The method thus enables the search for more active materials.

\section{Theoretical Method}

DFT calculations. - The DFT calculations of Ni-adsorbed species $\left(\mathrm{H}, \mathrm{C}, \mathrm{CH}, \mathrm{CH}_{2}, \mathrm{CH}_{3}, \mathrm{HCO}, \mathrm{O}, \mathrm{OH}\right.$, and $\left.\mathrm{CO}\right)$ are performed using a plane wave implementation, ${ }^{16}$ and the $\mathrm{RPBE}^{17}$ generalized gradient approximation for the exchange-correlation term. Calculations on close-packed surfaces (three-layer $\{111\}$ slabs) and on stepped surfaces (nine-layer $\{211\}$ slabs) are performed. These are taken as representative of a flat and stepped surface, respectively, and are chosen to mimic the local coordination of the terrace and edge atoms found on an active nanoparticle catalyst. It is well documented $^{18-22}$ that for certain reactions there is a pronounced structure sensitivity, where despite the terrace atoms being present in a larger number than edge atoms the difference in rates means that the edge atoms dominate the activity. For the close-packed surfaces we use a $2 \times 2$ surface unit cell and a $4 \times 4 \times 1$ Monkhorst-Pack $k$-point sampling. For the stepped surfaces a $3 \times 1$ unit cell and $4 \times$ $4 \times 1 k$-point sampling are applied. Ultrasoft pseudopotentials are employed to deal with the ion cores. ${ }^{23}$ The electronic wave functions are represented in a plane wave basis set with a cutoff energy of 340 
Table I. Energetics and thermodynamic quantities for reaction intermediates on Ni. The energetics of the intermediates and TSs are referenced to the gas-phase molecules $\mathrm{CH}_{4}, \mathrm{H}_{2} \mathrm{O}$, and $\mathrm{CO}_{2}$. Standard pressures are used in the free-energy calculations. The zero-point energies, entropies, and enthalpies (internal energies $U$ ) used to calculate the free energies $G$ are obtained using the calculated vibrational frequencies.

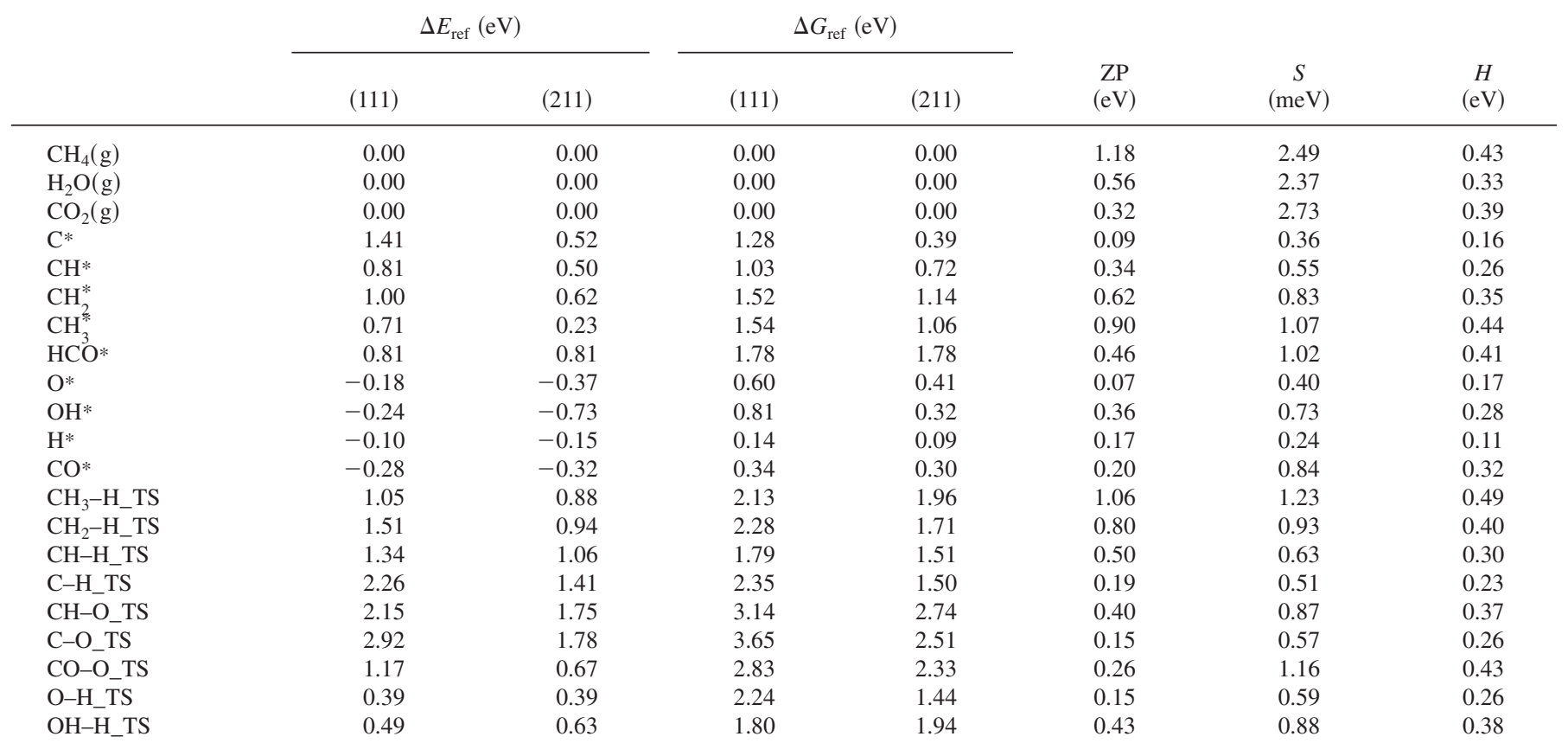

\begin{tabular}{|c|c|c|c|c|c|c|c|c|c|}
\hline \multirow[b]{2}{*}{ Reaction } & \multicolumn{2}{|c|}{$\Delta E(\mathrm{eV})$} & \multicolumn{3}{|c|}{$E_{\mathrm{a}}(\mathrm{eV})$} & \multicolumn{2}{|c|}{$\Delta G(\mathrm{eV})$} & \multicolumn{2}{|c|}{$G_{\mathrm{a}}^{0}(\mathrm{eV})$} \\
\hline & 111 & 211 & 111 & 211 & UQ & 111 & 211 & 111 & 211 \\
\hline $\mathrm{O}^{2-}(\mathrm{elec})+* \rightarrow \mathrm{O}^{*}+2 \mathrm{e}^{-}$ & -0.18 & -0.37 & - & - & - & 0.60 & 0.41 & - & - \\
\hline $\mathrm{CH}_{4}(\mathrm{~g})+2^{*} \rightarrow \mathrm{CH}_{3}^{*}+\mathrm{H}^{*}$ & 0.54 & 0.08 & 1.05 & 0.88 & 0.60 & 1.61 & 1.15 & 2.13 & 1.96 \\
\hline $\mathrm{CH}_{3}^{*}+* \rightarrow \mathrm{CH}_{2}^{*}+\mathrm{H}^{*}$ & 0.14 & 0.25 & 0.80 & 0.71 & 1.04 & 0.06 & 0.17 & 0.74 & 0.65 \\
\hline $\mathrm{CH}_{2}^{*}+* \rightarrow \mathrm{CH}^{*}+\mathrm{H}^{*}$ & -0.46 & -0.38 & 0.34 & 0.44 & 1.01 & -0.52 & -0.44 & 0.27 & 0.37 \\
\hline $\mathrm{CH}^{2}+* \rightarrow \mathrm{C}^{*}+\mathrm{H}^{*}$ & 0.56 & -0.07 & 1.45 & 0.91 & 0.20 & 0.44 & -0.19 & 1.32 & 0.78 \\
\hline $\mathrm{C}^{*}+\mathrm{O}^{*} \rightarrow \mathrm{CO}^{*}+*$ & -1.48 & -0.59 & 1.69 & 1.63 & 1.53 & -1.51 & -0.62 & 1.77 & 1.71 \\
\hline $\mathrm{CH}^{*}+\mathrm{O}^{*} \rightarrow \mathrm{HCO}^{*}+*$ & 0.25 & 0.61 & 1.52 & 1.62 & - & 0.21 & 0.57 & 1.51 & 1.61 \\
\hline $\mathrm{HCO}^{*}+* \rightarrow \mathrm{H}^{*}+\mathrm{CO}^{*}$ & -1.15 & -1.28 & 0.34 & 0.27 & - & -1.26 & -1.39 & 0.26 & 0.19 \\
\hline $\mathrm{O}^{*}+\mathrm{H}^{*} \rightarrow \mathrm{OH}^{*}+*$ & 0.45 & -0.19 & 1.47 & 0.91 & 1.01 & 0.49 & -0.15 & 1.50 & 0.94 \\
\hline $\mathrm{OH}^{*}+\mathrm{H}^{*} \rightarrow \mathrm{H}_{2} \mathrm{O}(\mathrm{g})+2^{*}$ & 0.05 & 0.85 & 0.83 & 1.51 & 0.44 & -1.23 & -0.43 & 0.85 & 1.53 \\
\hline $\mathrm{CO}^{*}+\mathrm{O}^{*} \rightarrow \mathrm{CO}_{2}(\mathrm{~g})+2^{*}$ & 0.40 & 0.86 & 1.63 & 1.36 & 1.28 & -1.00 & -0.54 & 1.89 & 1.62 \\
\hline
\end{tabular}

$\mathrm{eV}$. The electron density is treated on a grid corresponding to a plane wave cutoff of $500 \mathrm{eV}$. A Fermi smearing of $0.1 \mathrm{eV}$ and Pulay mixing are used to ensure a fast convergence of the self-consistent electron density. The bottom layers of the slabs are fixed at the optimized bulk lattice constants while the top atomic layers (defining the surface of the substrate) as well as the adsorbate's ionic positions are relaxed until the sum of the absolute forces is less than 0.05 eV/Å. All calculations are performed using Dacapo and the ASE simulation package. ${ }^{24}$

The barriers ${ }^{\mathrm{d}}$ and transition states (TSs) in the considered reaction processes are located using the nudged elastic band (NEB) method. ${ }^{25}$ Images (7-11, including endpoints) are used to describe the paths between the different stable intermediates. The images are

\footnotetext{
${ }^{d}$ All barriers except $\mathrm{CO}$ oxidation are handled with the NEB; the CO oxidation barriers are calculated with the constrained minimization technique.
}

relaxed until the change in energy is less than $0.001 \mathrm{eV}$. The configuration for which the energy is highest (termed the TS) is determined.

The DFT adsorption energetics of intermediates is shown in Table I, and the reaction energetics including barriers for the elementary reactions investigated is shown in Table II. More details about the adsorption structure of the intermediates and their TSs can be found in Ref. 26.

In Table II we have furthermore compared our reaction barriers on steps and terraces, with the activation barriers obtained by a unity-bond-index-quadratic-exponential-potential (UQ) approach used in Ref. 27. The activation barriers differ significantly. Furthermore, the UQ method does not distinguish between facet and step sites, nor does it prove thermodynamically consistent. This means that the reaction energies obtained by subtracting forward and backward activation energies are severely different from our calculated 
reaction energies. This illustrates the importance of first-principles insight into these complicated and interrelated processes for which fitting approaches are inherently difficult to validate and apply.

Thermodynamic corrections. - The high operational temperature of the SOFC necessitates a description of the change in free energy under the oxidation process. We use the simple approach described in Ref. 28 to calculate the Gibbs free-energy changes and set the operational temperature $(T)$ of the fuel cell to be $900 \mathrm{~K}$.

The Gibbs free energy of the gas-phase molecules is calculated as

$$
G_{\mathrm{gas}}^{\mathrm{p}, T}=E+E_{\mathrm{ZP}}+\Delta H_{\mathrm{gas}}^{0, T}-T S_{\mathrm{gas}}^{T}+k_{\mathrm{B}} T \log \left(p / p^{0}\right)
$$

including the DFT calculated energy $(E)$ of the gas-phase molecule with zero-point correction $\left(E_{\mathrm{ZP}}\right)$, the enthalpy change $\left(\Delta H_{\text {gas }}^{0, T}\right)$ when raising the temperature from $0 \mathrm{~K}$ to $T$, the entropic contribution $\left(T S_{\text {gas }}^{T}\right)$, and finally the Boltzmann constant $\left(k_{\mathrm{B}}\right)$ enters in the pressure-volume work. For the gas-phase enthalpy change and entropy we use standard tabulated values from Ref. 29 and 30.

To calculate the free energy of surface adsorbed species $X^{*}$ we use

$$
G_{X_{*}^{\mathrm{p}}}^{\mathrm{p} T}=E_{X_{*}}+E_{\mathrm{ZP}}-T S_{\mathrm{vib}}^{T}+\Delta U_{\mathrm{vib}}^{0, T}
$$

Here $E_{X_{*}}=E(X+\operatorname{surf})-E(\operatorname{surf})$ is a measure of the binding strength of $X$ to the surface, which is either evaluated directly from DFT calculations or via scaling relations. The pressure term vanishes at the surface, such that the enthalpy change $\left(\Delta H_{\mathrm{gas}}^{0, T}\right)$ in Eq. 1 is substituted by the change in internal energy $\left(\Delta U_{\mathrm{vib}}^{0, T}\right)$. The rotational degrees of freedom are converted to frustrated rotations on the surface, and consequently the changes in the entropy and internal energy only include vibrational components for the adsorbed species. The zero-point correction and the energetic changes due to the vibrational degrees of freedom are calculated from $i$ vibrational frequencies $\left(v_{\mathrm{i}}\right)$ obtained from DFT displacement calculations assuming harmonic modes. Explicitly, in the harmonic approximation that we employ, the vibrationally dependent terms read ${ }^{31}$

$$
\begin{gathered}
E_{\mathrm{ZP}}=\frac{1}{2} \sum_{\mathrm{i}} h v_{\mathrm{i}} \\
T S_{\text {vib }}^{T}=\sum_{\mathrm{i}} \frac{h v_{\mathrm{i}}}{\mathrm{e}^{h v_{\mathrm{i}} / k_{\mathrm{B}} T}-1}-k_{B} T \sum_{\mathrm{i}} \ln \left(1-\mathrm{e}^{-h v_{\mathrm{i}} / k_{\mathrm{B}} T}\right)
\end{gathered}
$$

and

$$
\Delta U_{\mathrm{vib}}^{0, T}=\sum_{\mathrm{i}} \frac{h v_{\mathrm{i}}}{e^{h v_{\mathrm{i}} k_{\mathrm{B}} T}-1}
$$

where $h$ is Planck's constant. Clearly there are issues when using the harmonic approximation to calculate the entropy and internal energy contribution from low vibrational modes, which can give spurious and significant corrections. Some of the low mode spurious behavior is diminished as the first entropy term is canceled by the internal energy contribution, and only the logarithmic term survives. Under all circumstances, at the elevated temperatures considered in this study, it is deemed that a significant source of error would persist if we were to ignore the thermodynamic contributions.

The thermodynamic corrections for all intermediates are given in Table I. The vibrational frequencies as well as the Shomate coefficient used to calculate the thermodynamic corrections are given in the supplementary materials. ${ }^{59}$ The impact of the stability of intermediates and reaction energetics is shown for standard pressure conditions in Tables I and II, respectively.

\section{Methane Oxidation}

The oxidation process of both hydrogen and methane have been intensively studied experimentally as well as theoretically. ${ }^{32-34}$ The hydrogen oxidation reaction has been the subject of numerous stud-

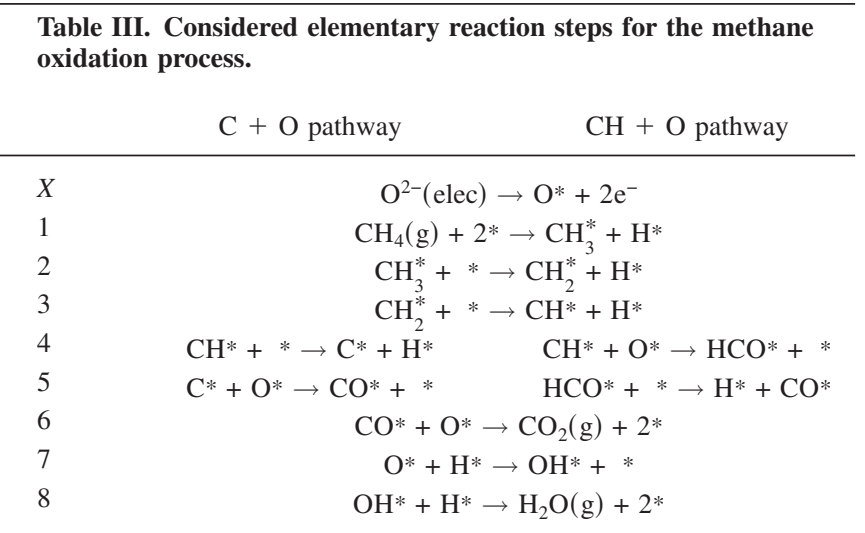

ies. The seemingly simple process has many different pathways by which it can proceed. The most dominant pathways proposed are bulk transport, ${ }^{35-37}$ hydrogen spillover, ${ }^{38,39}$ and oxygen spillover. $^{40-43}$

It is generally believed that the surface processes of hydrogen and methane oxidation for the most commonly used catalyst, the Ni-YSZ cermet, are fast. ${ }^{44}$ Recent studies suggest that chargetransfer and hydrogen spillover reactions are rate-limiting steps for this material. ${ }^{41,45}$ Pressure conditions may also influence which reaction steps become rate-limiting. ${ }^{45}$ To further complicate the reaction process, the electrolyte material may also play an important role. For instance, commonly used electrolyte materials such as YSZ and $\mathrm{CeO}_{2}$ have been shown to be active catalytic materials. ${ }^{46,47}$ This makes it hard to distinguish the catalytic effects of the anode vs the electrolyte.

Due to the high number of possible intermediates in the methane oxidation process, it is inherently more complicated than the hydrogen oxidation process. Spatial-resolved kinetic modeling studies suggest that methane is steam reformed at the anode to produce carbon monoxide and hydrogen. Hydrogen is subsequently transported to the three-phase boundary where it is oxidized. ${ }^{27,48,49}$

Despite the many complexities, we focus on the anode surface reactions at zero overpotential and assume the oxygen spillover pathway. We thus ignore effects such as mass transport, bulk pathways, charge transfer, and the role of the electrolyte. However crude such an approach might appear, it has previously been successfully applied $^{8,9}$ to describe the hydrogen oxidation activity trend of SOFCs assuming an oxygen spillover pathway. We proceed along a similar path to describe the SOFC activity for the methane oxidation process. In the oxygen spillover picture, the complicated oxidation process is transformed to a simple problem that only involves the adsorption energetics of anode surface intermediates.

In the earlier studies, a simple energetic picture was applied to successfully establish a trend description in terms of the oxygen adsorption energy. We further elaborate the model to describe the methane combustion process. To probe the low temperature regime, where the effect of the anode activity is most pronounced we use $900 \mathrm{~K}$ as the operational temperature.

Reaction pathways. - We focus on the methane oxidation process in fuel cells, where the overall reaction reads

$$
\mathrm{CH}_{4}(\mathrm{~g})+2 \mathrm{O}_{2}(\mathrm{~g}) \rightarrow \mathrm{CO}_{2}(\mathrm{~g})+2 \mathrm{H}_{2} \mathrm{O}(\mathrm{g})
$$

For the hydrogen fuel cell, only $\mathrm{OH}^{*}, \mathrm{O}^{*}$, and $\mathrm{H}^{*}$ are relevant intermediates, and the complexity of the reaction pathway is therefore inherently limited. The methane oxidation process includes many possible intermediates, elementary reaction steps, and pathways. For instance, Hecht et al. included 21 elementary reaction steps within their model. ${ }^{27}$ We take a simplistic approach and restrict ourselves to the two reaction pathways $(\mathrm{C}+\mathrm{O}$ and $\mathrm{CH}+\mathrm{O})$ shown in Table III, where we only consider nine different reaction steps. 
The $\mathrm{C}+\mathrm{O}$ and $\mathrm{CH}+\mathrm{O}$ pathways differ in the way the surface adsorbed $\mathrm{CO}$ is formed. In the $\mathrm{C}+\mathrm{O}$ pathway, we assume full dehydrogenation of methane, water formation, and finally $\mathrm{CO}_{2}$ formation. The $\mathrm{CO}$ intermediate is formed simply by the combination of surface adsorbed carbon and oxygen. On the $\{111\}$ surface, the $\mathrm{CO}$ formation step has a large energetic barrier that strongly inhibits the $\mathrm{C}+\mathrm{O}$ pathway. This barrier is circumvented in the $\mathrm{CH}+\mathrm{O}$ pathway, where methane only dehydrogenates until $\mathrm{CH}$ is formed. $\mathrm{CH}$ is then oxidized, forming $\mathrm{HCO}$, which reduces to surface adsorbed $\mathrm{H}$ and $\mathrm{CO}$. This observation is consistent with previous findings. 10,11

Electrolyte oxygen delivery potential.- One key ingredient for the oxidation process is the reaction energy for delivering oxygen from the electrolyte to the anode surface corresponding to the reaction

$$
\mathrm{O}^{2-}(\mathrm{elec}, \text { ano })+* \rightarrow \mathrm{O}^{*}+2 \mathrm{e}^{-}
$$

To estimate the reaction energy of this process, we proceed along the path outlined in Ref. 8 and 9. We focus on the anode side of the reaction and assume the cathode half-cell reaction

$$
1 / 2 \mathrm{O}_{2}(\mathrm{~g})+2 \mathrm{e}^{-} \rightarrow \mathrm{O}^{2-}(\text { elec, cat })
$$

to be equilibrated. Explicitly, the free-energy change in the cathode is

$$
\Delta G_{\text {cat }}=4 G\left(\mathrm{O}^{2-}, \text { cat }\right)-\left[2 G\left(\mathrm{O}_{2}\right)-8 U_{\text {cat }} \mathrm{e}\right]=0
$$

where $U_{\text {cat }}\left(U_{\text {ano }}\right)$ denotes the potential at the cathode (anode).

Furthermore, we assume the electrolyte to be ideal so that we have no resistance in the electrolyte. Consequently

$$
G\left(\mathrm{O}^{2-}, \text { cat }\right)=G\left(\mathrm{O}^{2-} \text {, ano }\right)
$$

The oxygen delivery potential can then be written

$$
\begin{aligned}
\Delta G_{\mathrm{x}, \text { ano }} & =G\left(\mathrm{O}^{*}\right)-2 \mathrm{e} U_{\text {ano }}-G\left(\mathrm{O}^{2-}, \text { ano }\right) \\
& =G\left(\mathrm{O}^{*}\right)-2 \mathrm{e} U_{\text {ano }}-G\left(\mathrm{O}^{2-}, \text { cat }\right)
\end{aligned}
$$

which by using the cathode equilibrium condition becomes

$$
\Delta G_{\mathrm{x}, \text { ano }}=G\left(\mathrm{O}^{*}\right)-2 \mathrm{e}\left(U_{\text {ano }}-U_{\text {cat }}\right)-\frac{1}{2} G\left(\mathrm{O}_{2}\right)
$$

To determine the potential difference $U_{\text {cat }}-U_{\text {ano, }}$, we note that the overall change in free energy of the methane combustion reaction

$$
\mathrm{CH}_{4}+2 \mathrm{O}_{2} \rightarrow 2 \mathrm{H}_{2} \mathrm{O}+\mathrm{CO}_{2}
$$

includes eight electron transfers in each half-cell reaction and reads

$$
\Delta G_{\mathrm{tot}}=\Delta G_{\mathrm{cat}}+\Delta G_{\mathrm{ano}}=-8 \mathrm{e} \eta
$$

where the overpotential $\eta$ is introduced. $\eta=0$ corresponds to opencircuit voltage (OCV) used for the energetic analysis in Ref. 8. In this picture the potential difference for the overall reaction is found from

$$
-8 \mathrm{e} \eta=\Delta G\left(\mathrm{CH}_{4}+2 \mathrm{O}_{2} \rightarrow 2 \mathrm{H}_{2} \mathrm{O}+\mathrm{CO}_{2}\right)+8 \mathrm{e}\left(U_{\text {cat }}-U_{\text {ano }}\right)
$$

such that the anode delivery potential finally reads

$$
\begin{aligned}
\Delta G_{x, \text { ano }}\left(\mathrm{O}^{2-}+* \rightarrow\right. & \left.\mathrm{O}^{*}+2 \mathrm{e}^{-}\right)=\Delta G\left(\frac{1}{4} \mathrm{CO}_{2}+\frac{1}{2} \mathrm{H}_{2} \mathrm{O}+* \rightarrow \mathrm{O}^{*}\right. \\
& \left.+\frac{1}{4} \mathrm{CH}_{4}\right)-2 \mathrm{e} \eta
\end{aligned}
$$

In the forthcoming analysis we keep $\eta=0$. In this perspective, the whole anode oxidation process can be described in terms of easily accessible quantities, and the search for an optimal catalyst becomes a "classical heterogeneous catalysis" problem. In this picture, the methane oxidation process is closely related to the problem of steam reforming recently discussed from a similar perspective in Ref. 51. In fact, at the chosen reaction conditions $(900 \mathrm{~K}$ and standard pressures) the steam-reforming reaction is close to equilibrium $(\Delta G=$ $-0.02 \mathrm{eV}$ ). Combined with subsequent syngas and hydrogen combustion, we essentially pass through the same reaction steps, as outlined in Table III. Furthermore, as $\eta$ is kept to zero potential, the
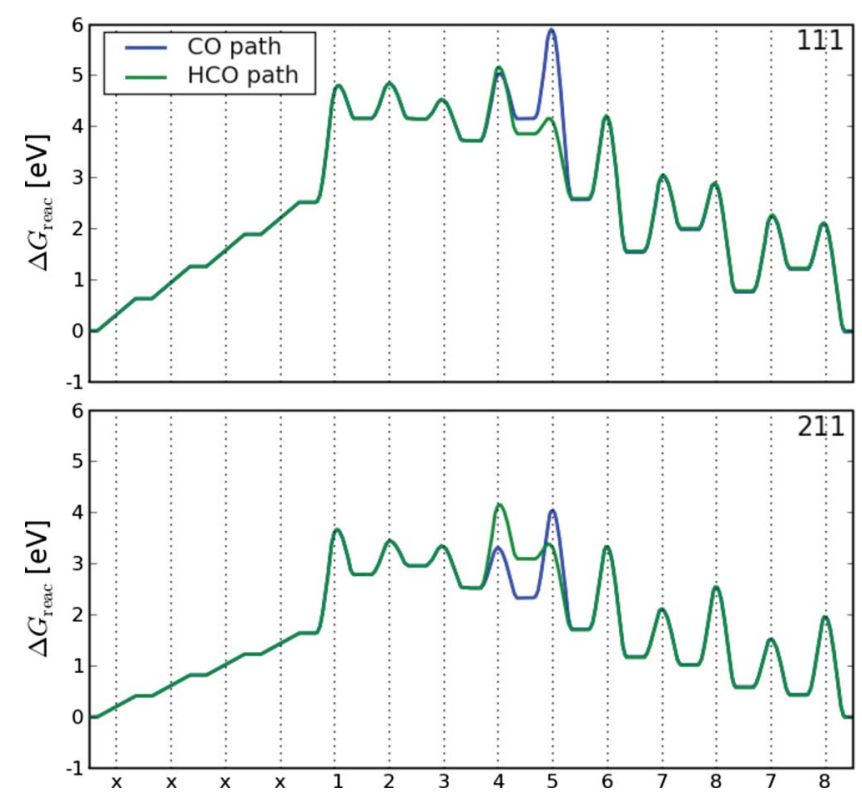

Figure 1. (Color online) The reaction energies and barriers for the elementary steps in the anode combustion process on $\mathrm{Ni}$ at $900 \mathrm{~K}$ and zero driving potential are shown. Both the $\mathrm{C}+\mathrm{O}$ pathway and the $\mathrm{CH}+\mathrm{O}$ pathway are shown. The upper (lower) inset corresponds to the $\{111\}$ terrace $(\{211\}$ stepped) surface. The $x$ axis indicates the reaction step for the two pathways, where the indexes correspond to the elementary reaction step outlined in Table I.

steam-reforming pathway is implicitly included in the forthcoming analysis of the proposed reaction mechanisms.

\section{Anode Reaction Analysis: A Trend Description}

The analysis is divided into three parts. First, the reaction mechanism on $\mathrm{Ni}$ is investigated in detail, calculating all intermediates and reaction barriers on the $\{111\}$ and $\{211\}$ model surfaces. Second, the reaction energies of the elementary steps on $\mathrm{Au}, \mathrm{Ag}, \mathrm{Cu}, \mathrm{Pd}, \mathrm{Pt}, \mathrm{Ir}$, $\mathrm{Rh}, \mathrm{Ru}, \mathrm{Co}, \mathrm{Mo}, \mathrm{W}\{111\}$, and $\{211\}$ are obtained via scaling relations of the intermediates, providing the basis for a simplified trend study. Finally, barriers and kinetic effects are included in the trend study, providing further insight into the possible candidates for methane oxidation catalysts.

Reaction energetics on $\mathrm{Ni}$.- In Fig. 1, we show the calculated free reaction energies and barriers on $\mathrm{Ni}$ for both the $\mathrm{C}+\mathrm{O}$ and $\mathrm{CH}$ $+\mathrm{O}$ reaction pathways. The free energies are evaluated at $900 \mathrm{~K}$ and standard pressure conditions. For the energetic analysis we use the zero overpotential $(\mathrm{OCV})$ when determining the oxygen delivery potential.

We start by determining which reaction pathway is the most favorable on the stepped and flat surfaces, respectively. On the stepped surface, the $\mathrm{C}+\mathrm{O}$ step (step 5 in the $\mathrm{CO}$ pathway) is slightly lower than the $\mathrm{CH}+\mathrm{O}$ recombination (step 4 in the $\mathrm{HCO}$ pathway), which suggests that the $\mathrm{C}+\mathrm{O}$ pathway is the preferred pathway on Ni $\{211\}$.

For the terraces $\{111\}$, the barrier for the $\mathrm{C}+\mathrm{O}$ formation is much larger than the corresponding $\mathrm{CH}+\mathrm{O}$ step, and thus this reaction proceeds through the $\mathrm{CH}+\mathrm{O}$ mechanism.

The energetic analysis also reveals that it is less energetically demanding to make the reaction run on the stepped surface than on the terraces, both from an overall energetic perspective and on the level of the individual barriers. From an overall energy perspective, we have to climb $6 \mathrm{eV}$ on the terraces, whereas on the stepped surfaces it suffices to climb $4 \mathrm{eV}$ to make the reaction proceed. On the level of the individual heights of the barriers, the largest barrier on both surfaces (the first step in the methane dehydrogenation process) is larger on the $\{111\}$ surface by $0.3 \mathrm{eV}$. This first barrier for 
Table IV. Adsorption energies of the surface species on Ni referenced to $\mathrm{CH}_{4}(\mathrm{~g}), \mathrm{CO}_{2}(\mathrm{~g})$, and $\mathrm{H}_{2} \mathrm{O}(\mathrm{g})$ as well as scaling coefficients to extend the $\mathrm{Ni}$ calculations to general materials.

\begin{tabular}{|c|c|c|c|c|c|c|}
\hline \multirow[b]{2}{*}{ Species } & \multicolumn{2}{|c|}{$\Delta E_{\text {ref }}(\mathrm{eV})$} & \multicolumn{2}{|c|}{$\gamma_{\mathrm{i}}$} & \multicolumn{2}{|c|}{$\delta_{\mathrm{i}}(\mathrm{eV})$} \\
\hline & (111) & (211) & (111) & (211) & (111) & (211) \\
\hline $\mathrm{C}^{*}$ & 1.41 & 0.52 & $1.00 \cdot \mathrm{C}$ & $1.00 \cdot \mathrm{C}$ & 0.00 & 0.00 \\
\hline $\mathrm{CH}^{*}$ & 0.81 & 0.50 & $0.75 \cdot \mathrm{C}$ & $0.75 \cdot \mathrm{C}$ & -0.25 & 0.11 \\
\hline $\mathrm{CH} 2 *$ & 1.00 & 0.62 & $0.50 \cdot \mathrm{C}$ & $0.50 \cdot \mathrm{C}$ & 0.30 & 0.36 \\
\hline $\mathrm{CH}_{3}^{*}$ & 0.71 & 0.23 & $0.25 \cdot \mathrm{C}$ & $0.25 \cdot \mathrm{C}$ & 0.36 & 0.10 \\
\hline HCO* & 0.81 & 0.81 & $0.43 \cdot \mathrm{C}$ & $0.43 \cdot \mathrm{C}$ & 0.20 & 0.59 \\
\hline $\mathrm{H}^{*}$ & -0.10 & -0.15 & $0.25 \cdot \mathrm{C}$ & $0.18 \cdot \mathrm{C}$ & -0.45 & -0.24 \\
\hline $\mathrm{CO}^{*}$ & -0.28 & -0.32 & $0.46 \cdot \mathrm{C}$ & $0.39 \cdot \mathrm{C}$ & -0.93 & -0.55 \\
\hline $\mathrm{O}^{*}$ & -0.18 & -0.37 & $1.00 \cdot \mathrm{O}$ & $1.00 \cdot \mathrm{O}$ & 0.00 & 0.00 \\
\hline $\mathrm{OH}^{*}$ & -0.24 & -0.73 & $0.50 \cdot \mathrm{O}$ & $0.50 \cdot \mathrm{O}$ & -0.15 & -0.55 \\
\hline
\end{tabular}

dehydrogenation of methane is strongly influenced by the temperature $^{50}$ as the main part of the barrier is due to the entropic loss when going from a gas-phase methane to the surface.

Materials screening through scaling relations.- The central tool that can be utilized to understand a given process within theoretical heterogeneous catalysis is an analysis of the reaction energies of the elementary steps. The materials with the smallest reaction energies are often good candidates as catalysts. This analysis provides a brief and simple overview of the reaction processes and has previously been used to study electrochemical methanol oxidation. ${ }^{51}$

Recently, the adsorption energies of hydrogenated carbon (oxygen, nitrogen, and sulfur) species were shown to scale linearly with the adsorption energies of the carbon (oxygen, nitrogen, and sulfur) atom for a range of transition-metal surfaces, and furthermore it was shown that the slope $\gamma_{\mathrm{i}}$ is given by $\left(x_{\max }-x\right) / x_{\max }$, where $x\left(x_{\max }\right)$ is the number of hydrogen atoms (maximum number of hydrogen atoms) bonded to atom i. ${ }^{12}$ We find phenomenologically similar linear relations, relating $\mathrm{H}^{*}, \mathrm{HCO}^{*}$, and $\mathrm{CO}^{*}$ adsorption energies to the carbon adsorption energies of the transition metals, thus allowing us to describe all reaction steps in terms of only two parameters: the carbon and the oxygen adsorption energies. We use the calculated adsorption energies over $\mathrm{Ni}$ to determine the offset parameter in the scaling relations. The slopes $\gamma_{\mathrm{i}}$ and offset parameters $\delta_{\mathrm{i}}$ used are tabulated in Table IV. The scaling relations extrapolated from the $\mathrm{Ni}$ results allow us to make an analysis of the energetics of the combustion process expressed solely in terms of the carbon and oxygen adsorption energies. The Gibbs free-energy change when going through the $\mathrm{C}+\mathrm{O}$ combustion pathway over the $\{111\}$ surface terrace is shown for many transition metals in Fig. 2. Clearly the more noble metals $\mathrm{Au}, \mathrm{Ag}, \mathrm{Cu}, \mathrm{Pt}, \mathrm{Pd}$, and $\mathrm{Ir}$ bind the reaction intermediates too weakly, leading to large energy costs for the adsorption processes, and these metals can therefore be ruled out as anode candidates. In contrast the more reactive metals, W, Mo, and $\mathrm{Fe}$, obviously bind oxygen too strongly, and we are thus left with four candidates, $\mathrm{Ni}, \mathrm{Rh}, \mathrm{Ru}$, and $\mathrm{Co}$ (indicated by full lines in the figure). Over these four metals both the adsorption and desorption reactions in the combustion process can proceed without excessively large reaction energy barriers. The above analysis is an example of a Sabatier analysis, ${ }^{14}$ where the intermediates of a reaction process should be available for surface reaction processes without large barriers as well as be able to desorb so that the surface is not selfpoisoned. This leads to the "optimal" catalyst being a compromise between adsorption and desorption reactions. A simple reactivity descriptor that roughly conforms with the Sabatier analysis is the "activity-descriptor," A, which for a given metal catalyst is determined from the largest reaction free energy step during the reaction process over that given metal

$$
A=-\max _{i}\left(\Delta G_{\text {reac }, \mathrm{i}}\right)
$$

Applying this simple descriptor, it is observed that the activity of tungsten should (as expected) mainly be hindered by desorption pro- cesses, while the activity of gold is inhibited by adsorption processes.

All reaction intermediates are calculated with the aid of scaling relations using only the adsorption energy of oxygen and carbon as input. This enables us to visualize the activity descriptor (Eq. 3) in terms of these two variables. The resulting activity volcanoes for all surfaces and pathways are shown in Fig. 3. The binding energies of carbon and oxygen of known transition metals are shown by crosses, which at the same time indicate the typical magnitude of uncertainty of DFT and scaling calculated energies of $0.2 \mathrm{eV}$. The volcano peak of the $\mathrm{C}+\mathrm{O}$ pathway over $\{111\}$ is clearly closest to the four candidates that were found optimal in Fig. 2. Furthermore, we observe that all the elemental metals are unable to bind carbon strongly enough to reach the top of the energy volcanoes. Also depicted (by enclosing contours) are the regimes ${ }^{32}$ of the most energetically demanding steps, and clearly these regimes form the shape of the volcano. Furthermore the optimum of the volcano is where the most reaction steps are in energetic balance with each other. The peak of the volcano points toward a regime of favorable adsorption properties of the optimal catalyst.

As the peak represents the compromise between different surface reactions, each with energetics based on several scaling relations which all have independent offset parameters and slopes, it is not

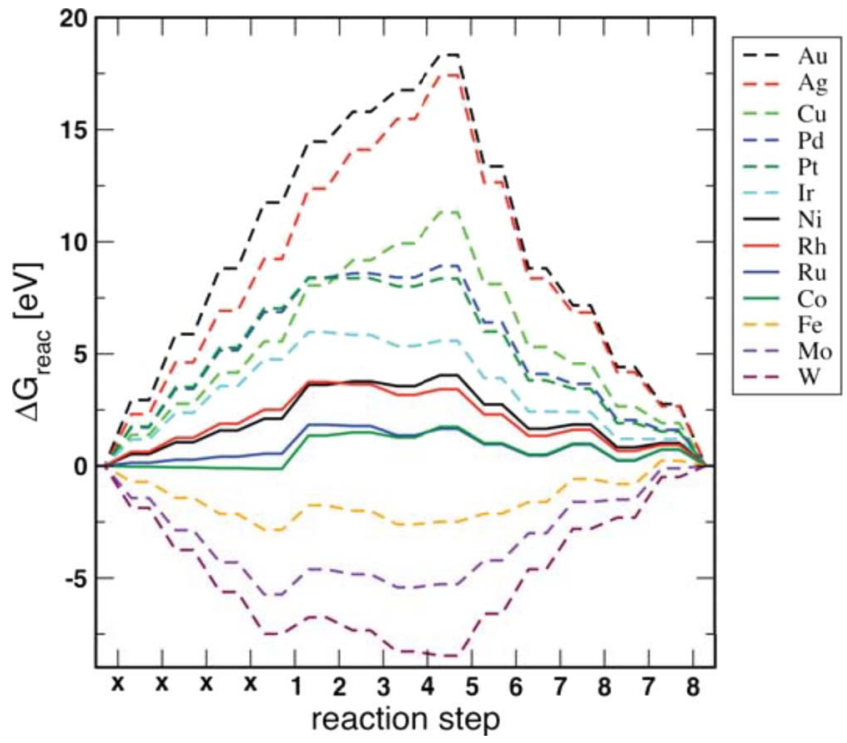

Figure 2. (Color online) Reaction energy change during the methane oxidation process on terrace surfaces evaluated by using scaling relations for many transition metals. The most promising candidates from an energetic viewpoint are shown with full lines. 


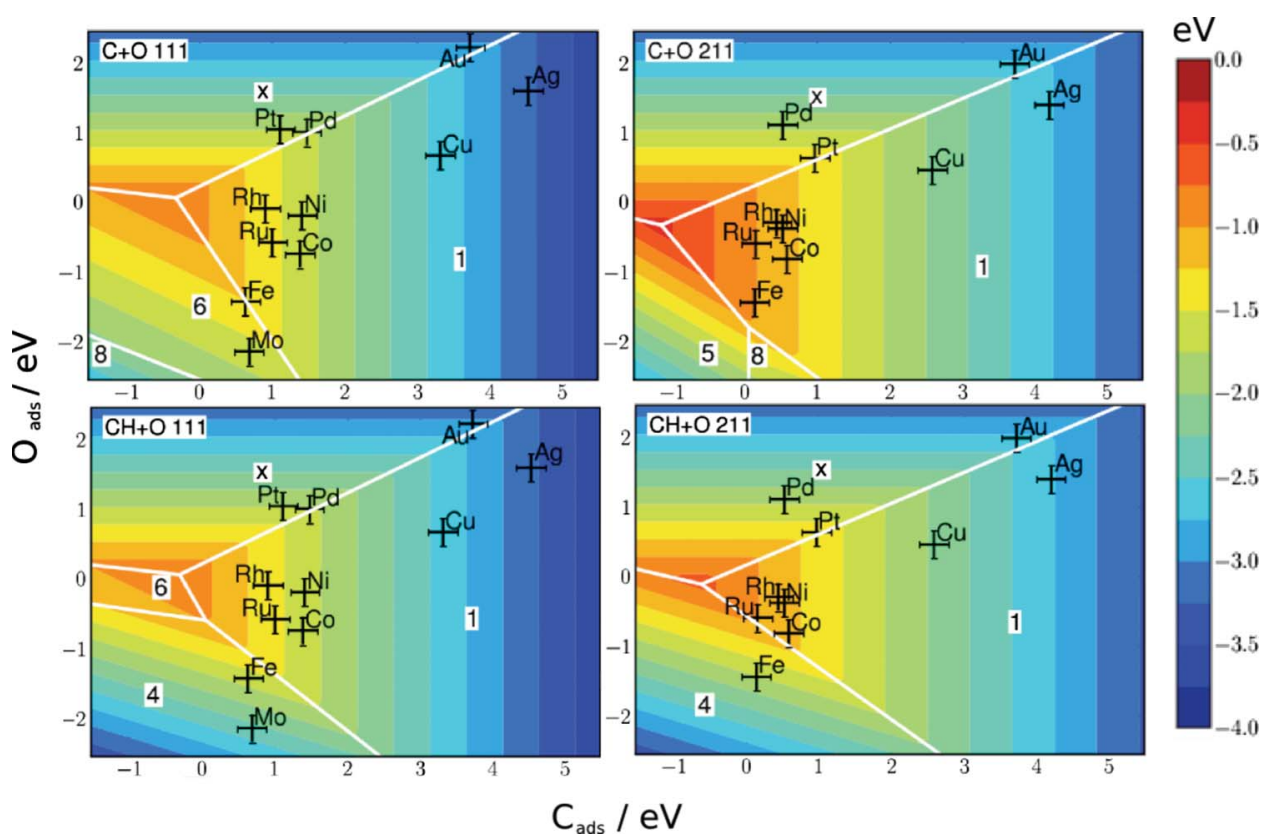

Figure 3. (Color online) Activity descriptor plotted as a function of the carbon and the oxygen adsorption strengths for the $\mathrm{C}$ $+\mathrm{O}$ mechanism (upper panels) and the $\mathrm{CH}+\mathrm{O}$ mechanism (lower panels) over the $\{111\}$ surfaces (left) and $\{211\}$ surfaces (right), respectively. The regimes of the most energetic demanding steps during the oxidation reaction are denoted by the reaction pathway identifier and are enclosed by the white lines. trivial to obtain the uncertainty of the position of the volcano peak. A rough estimate ${ }^{\mathrm{e}}$ finds the uncertainty of the volcano peak to be 0.4 $\mathrm{eV}$. Furthermore, it should be noted that in the energetic picture we neglect the influence of the pressure of gas-phase molecules. However, this effect is minor. For example, changing the pressure of $\mathrm{H}_{2} \mathrm{O}$ by 3 orders of magnitude only affects the energetics of the water formation Reaction "7" by $0.2 \mathrm{eV}$ at $900 \mathrm{~K}$ and the oxygen delivery Reaction " $\mathrm{x}$ " is changed by $0.1 \mathrm{eV}$. The energetic analysis shows the strength of the scaling methodology. Provided by a proper model and the determination of an appropriate activity descriptor, the region of good catalysts can be determined. This can subsequently be used in a search for interesting alloys guided by the volcano optimum in terms of easily calculated DFT values ${ }^{53}$ or estimated by a simple linear interpolation scheme. ${ }^{54}$

Kinetic modeling.- The analysis of reaction energetics provides insight into necessary but perhaps not sufficient aspects of the reaction. It is a fast way to roughly rank the catalytic activities of the different metals. However, the calculation of rates and detailed comparison between the catalysts cannot be done directly within this analysis. To calculate the reaction rates, it is necessary to know the reaction barriers and include intermediate coverages into the models.

$B E P$ relations. - The computational process of calculating reaction barriers is tedious, cumbersome, and can only be applied to known materials. It is at least an order of magnitude more computationally demanding than determining reaction energies. Thus it would not be consistent with the simple scaling picture to carry out such detailed calculations for many systems. Fortunately, the activation energy $E_{\mathrm{a}}$ of a given surface reaction step is often found to scale linearly with the reaction energy $\Delta E .^{13}$ Such linear relationships are known as Brønsted-Evans-Polanyi (BEP) relations and have the form $E_{\text {a }}$ $=\alpha \Delta E+\beta$, where $\alpha$ and $\beta$ are parameters obtained by fitting calculated barriers and adsorption energies.

Based on the TSs found over Ni we establish the approximate BEP relationships for the relevant reaction steps using a constrained minimization technique (CMT). In the CMT, initial configuration of

\footnotetext{
${ }^{\mathrm{e}}$ By considering the distance from the volcano peak to $\mathrm{Ni}$ (for which all data are calibrated) is on the order of $1-2 \mathrm{eV}$, a change in slope of 0.1 for one of the dividing lines that makes up the regions close to the volcano top would on average result in a change of $0.2 \mathrm{eV}$ of the peak position. We also assign an error of $0.2 \mathrm{eV}$ for the offset of these lines and thus roughly conclude that the volcano peak due to uncertainties in the scaling relations may change by $0.4 \mathrm{eV}$.
}

the surface adsorbed molecules with a single stretched bond closely, resembling the TS configuration on $\mathrm{Ni}$, is relaxed. Subsequently the bond is stretched and compressed. Hereby the TS and the barrier for an elementary step are determined. The figures of the established BEP lines are shown in the supplementary materials, ${ }^{59}$ and the BEP coefficients of the elementary reactions are given in Table $\mathrm{V}$. In the table, the offset value $\beta$ is calibrated for each elementary reaction such that the activation energy of $\mathrm{Ni}$ is reproduced.

All the necessary quantities for describing the kinetics of the reaction processes are therefore now given in terms of the carbon and oxygen adsorption energies, which opens up for a trend description in terms of actual reaction rates.

Rate constants and equilibrium constants. - The energetic description including the barriers of elementary reaction steps, augmented with the thermodynamic corrections, now enables us to construct kinetic models. Explicitly, the equilibrium constant $\left(K_{\mathrm{i}}\right)$ of a quasiequilibrated elementary step $i$ is related to the standard free-energy change $\left(\Delta G_{\mathrm{i}}^{0, T}\right)$ of the step as

\begin{tabular}{|c|c|c|c|c|}
\hline \multirow[b]{2}{*}{ Reaction } & \multicolumn{2}{|c|}{$\alpha_{\mathrm{BEP}}$} & \multicolumn{2}{|c|}{$\beta_{\mathrm{BEP}}(\mathrm{eV})$} \\
\hline & 111 & 211 & 111 & 211 \\
\hline $\mathrm{CH}_{4}(\mathrm{~g})+2^{*} \rightarrow \mathrm{CH}_{3}^{*}+\mathrm{H}^{*}$ & 0.61 & 0.81 & 0.72 & 0.82 \\
\hline $\mathrm{CH}_{3}^{*}+* \rightarrow \mathrm{CH}_{2}^{*}+\mathrm{H}^{*}$ & 0.83 & 0.96 & 0.68 & 0.47 \\
\hline $\mathrm{CH}_{2}^{*}+* \rightarrow \mathrm{CH}^{*}+\mathrm{H}^{*}$ & 0.86 & 0.91 & 0.74 & 0.79 \\
\hline $\mathrm{CH}^{2}+* \rightarrow \mathrm{C}^{*}+\mathrm{H}^{*}$ & 0.87 & 0.81 & 0.96 & 0.97 \\
\hline $\mathrm{C}^{*}+\mathrm{O}^{*} \rightarrow \mathrm{CO}^{*}+*$ & 0.42 & 0.29 & 2.31 & 1.8 \\
\hline $\mathrm{CH}^{*}+\mathrm{O}^{*} \rightarrow \mathrm{HCO}^{*}+*$ & 0.22 & 0.15 & 1.47 & 1.53 \\
\hline $\mathrm{HCO}^{*}+* \rightarrow \mathrm{H}^{*}+\mathrm{CO}^{*}$ & $\mathrm{QE}$ & $\mathrm{QE}$ & $\mathrm{QE}$ & $\mathrm{QE}$ \\
\hline $\mathrm{O}^{*}+\mathrm{H}^{*} \rightarrow \mathrm{OH}^{*}+*$ & 0.38 & 0.41 & 1.30 & 0.99 \\
\hline $\mathrm{OH}^{*}+\mathrm{H}^{*} \rightarrow \mathrm{H}_{2} \mathrm{O}(\mathrm{g})+2^{*}$ & 0.43 & 0.52 & 0.81 & 1.07 \\
\hline $\mathrm{CO} *+\mathrm{O}^{*} \rightarrow \mathrm{CO}_{2}(\mathrm{~g})+2^{*}$ & 0.38 & 0.28 & 1.48 & 1.12 \\
\hline
\end{tabular}




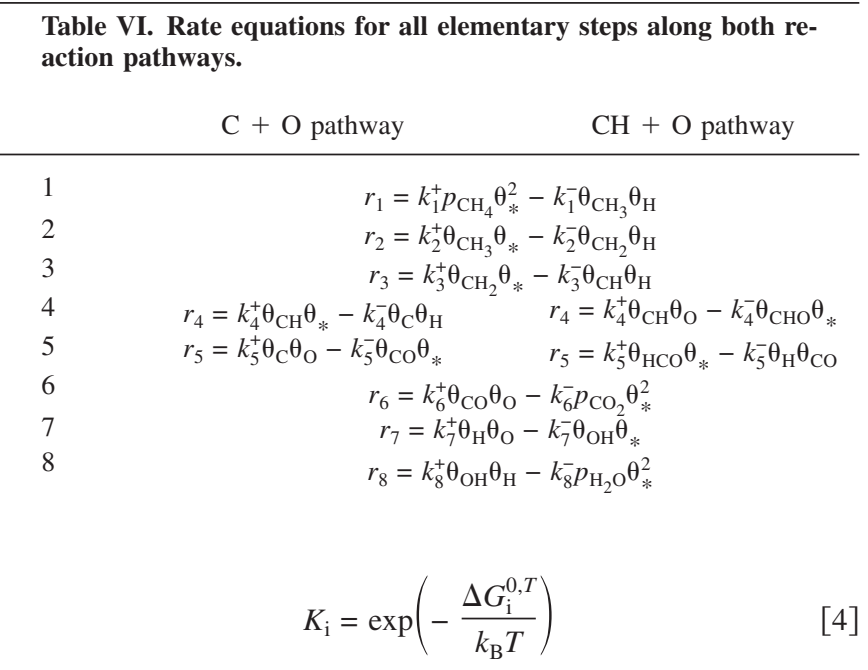

In the TS theory, the rate constant $\left(k_{\mathrm{i}}\right)$ reads

$$
k_{\mathrm{i}}^{ \pm}=\frac{k_{\mathrm{B}} T}{h} \exp \left(-\frac{G_{\mathrm{act}}^{ \pm}}{k_{\mathrm{B}} T}\right)
$$

where $G_{\text {act }}^{ \pm}$is the free energy of activation either in the forward (+) or backward (-) direction. Finally, we note that the equilibrium constants of the elementary reactions can be expressed in terms of the forward and backward rate constants as

$$
K_{\mathrm{i}}=\frac{k_{\mathrm{i}}^{+}}{k_{\mathrm{i}}^{-}}
$$

The energetic analysis presented earlier treats all the microscopic steps on the same footing and ignores the energy barriers for the specific reaction steps. Also the effects of intermediate coverages are ignored. To get a grip of the kinetics of the oxidation process, we approximate the full kinetic description by an analysis of the exchange kinetics at zero overpotential. This analysis essentially treats each of the elementary steps as a RDS in sequence, while the rest of the steps are assumed quasi-equilibrated. The overall reaction rate is then approximated by the forward rate of the slowest reaction step during the reaction process. This approach is very useful for small driving forces (where the overall free energy of reaction is only slightly negative), in which case well-defined chemical potentials can be assigned to all reactants, products, and surface adsorbed species. The approach allows us to estimate the rate-limiting reaction steps during the reaction process and reveals the candidates that are most likely to be good catalysts.

In the Electrolyte oxygen delivery potential section, we found the oxygen delivery potential to be

$$
\begin{aligned}
\Delta G_{\text {ano }}\left(\mathrm{O}^{2-}+^{*} \rightarrow\right. & \left.\mathrm{O}^{*}+2 \mathrm{e}^{-}\right)=\Delta G\left(\frac{1}{4} \mathrm{CO}_{2}+\frac{1}{2} \mathrm{H}_{2} \mathrm{O}+^{*} \rightarrow \mathrm{O}^{*}\right. \\
& \left.+\frac{1}{4} \mathrm{CH}_{4}\right)-2 \mathrm{e} \eta
\end{aligned}
$$

We assume the delivery step to be quasi-equilibrated such that the oxygen coverage $\theta_{\mathrm{O}}$ can be related to the coverage of free sites $\theta_{*}$ as

$$
\theta_{\mathrm{O}}=K_{\mathrm{ano}}\left(p_{\mathrm{H}_{2}} p_{\mathrm{CO}_{2}} p_{\mathrm{CH}_{4}}^{-1}\right)^{1 / 4} \theta_{*} \equiv \gamma_{\mathrm{O}} \theta_{*}
$$

where the equilibrium constant $K_{\text {ano }}$ is found by applying Eq. 4 on the anode delivery potential.

The rate equations for the remaining steps are shown in Table VI. The approach sequentially treats each step as if it was the RDS, i.e., $r_{\mathrm{i}} \equiv \overrightarrow{\mathrm{RDS}, \mathrm{i}}$, where only the forward rate is considered in the analysis. The remaining steps are quasi-equilibrated: $r_{\mathrm{j} \neq \mathrm{i}}=0$.

The quasi-equilibrated steps allow us to determine the coverage of any surface specie $i$ as a well-defined fraction $\gamma_{\mathrm{i}}$ of the coverage of free sites $\theta_{*}$ or explicitly $\theta_{\mathrm{i}}=\gamma_{\mathrm{i}} \theta_{*}$. The free site coverage now follows from the constraint that the sum of all coverages (including the free sites) must sum up to 1 , which gives us the following simple relation for the fractional coverage of free sites

$$
\theta_{*}=\left(1+\sum_{\mathrm{i}} \gamma_{\mathrm{i}}\right)^{-1}
$$

With this relation, all the coverages entering the rate equations are determined, allowing the evaluation of $\overrightarrow{\mathrm{RDS}, \mathrm{i}}$. Finally, the overall exchange rate $r_{\Sigma}$ is given by

$$
r_{\Sigma}=\min _{\mathrm{i}} \underset{\mathrm{RDS}, \mathrm{i}}{\overrightarrow{\mathrm{C}}} .
$$

Exchange activity landscapes.- We have mapped out the methane oxidation activity using the scaling relations to determine the reaction energy differences and BEP relations to find the reaction barriers. The potential energy diagram for all the surfaces in terms of the oxygen and carbon binding strength can thus be established. The potential energy diagrams are input to the kinetic method used to calculate the overall reaction rates for a range of carbon and oxygen adsorption energies. We have plotted such activity landscapes at standard pressures in Fig. 4. The activity is divided into regions, showing the overall RDSs, and we observe that closest to the activity optimum, the first methane dehydrogenation step, the $\mathrm{CO}$ forming step (alternatively the $\mathrm{HCO}$ forming step), and the $\mathrm{H}_{2} \mathrm{O}$ forming

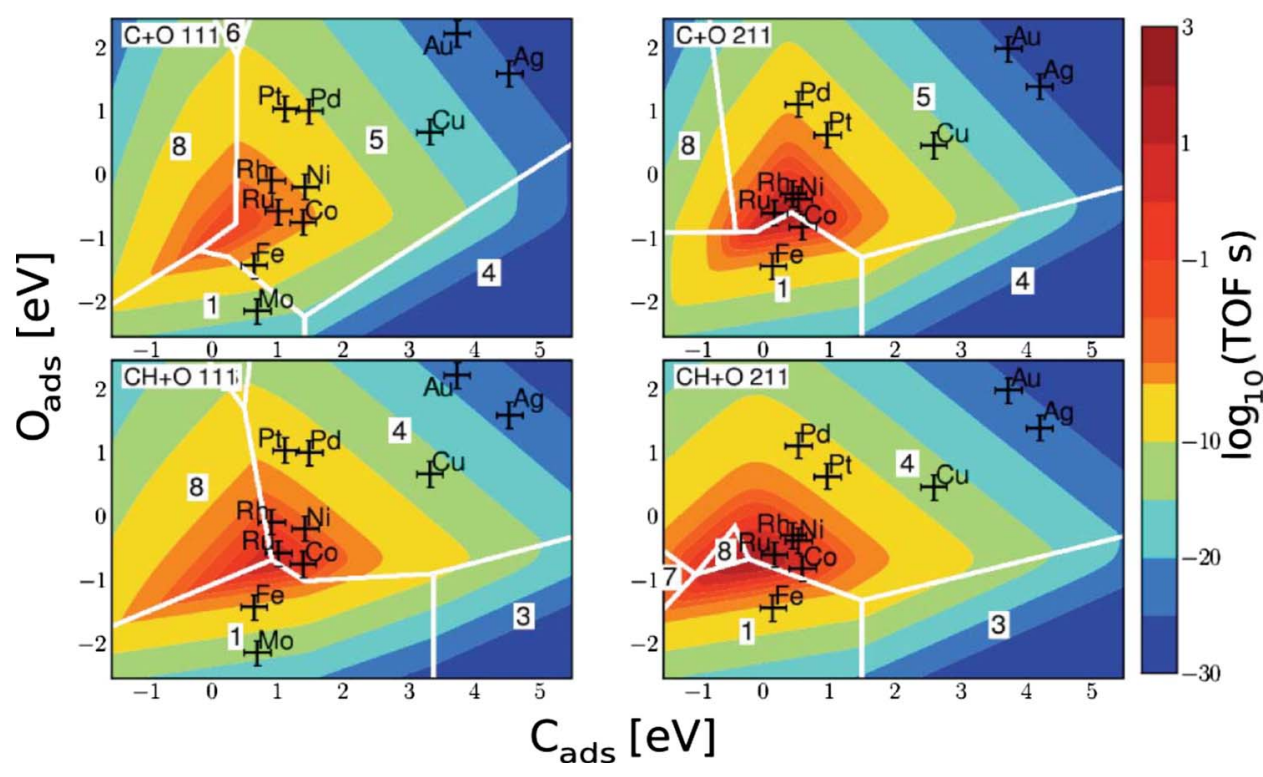

Figure 4. (Color online) Exchange activity plots in the single RDS approximation. $\log _{10}$ of the exchange turnover frequency is mapped out in terms of the carbon and oxygen surface adsorption strengths for all the mechanisms and on all surface types. Furthermore, the activity plots are divided into regions, where different RDSs limit the activity. These regions are shown with white boundaries, and the reaction pathway identifier denotes the associated limiting step. 


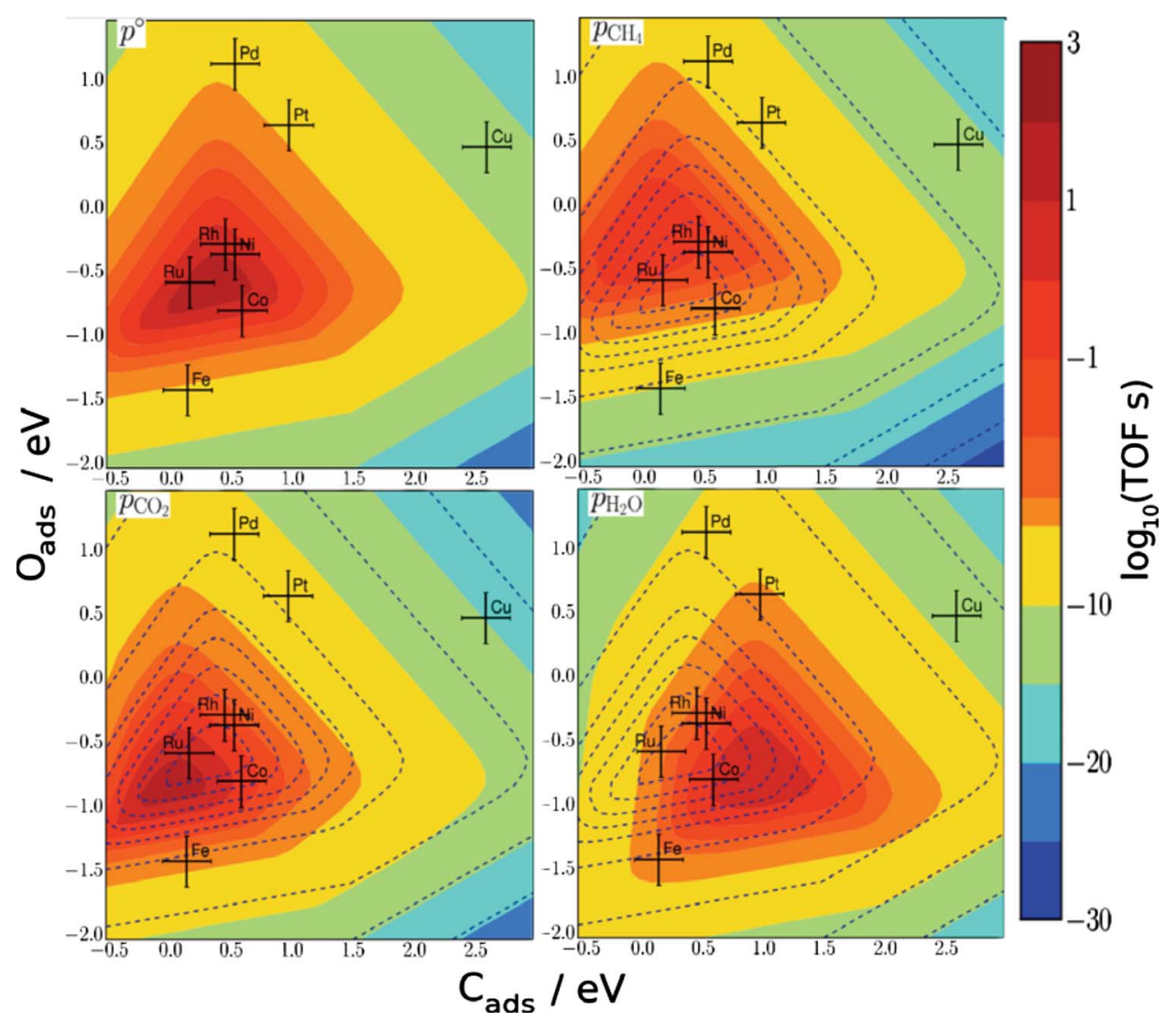

Figure 5. (Color online) Pressure dependence of the $\mathrm{C}+\mathrm{O} 211$ activity volcano shown by varying the pressures of $\mathrm{CH}_{4}$, $\mathrm{H}_{2} \mathrm{O}$, and $\mathrm{CO}_{2}$ individually. The pressures of the gas-phase molecules are changed in turn from standard pressure to 1 mbar. The activity at standard pressure conditions is shown for reference and indicated by dashed contour lines in subsequent plots. The activity is plotted as $\log _{10}$ of the turnover frequency. step can be considered as RDSs. It should be noted that the second slowest step (e.g., over Ni) is typically 2 orders of magnitude faster than the slowest step. This justifies the quasi-equilibrium approximations for the remaining reaction steps.

For both mechanisms over both steps and terraces, $\mathrm{Ru}, \mathrm{Ir}, \mathrm{Co}, \mathrm{Ni}$, and $\mathrm{Rh}$ show up as the best elemental candidates. Especially noteworthy is $\mathrm{Ru}$, which for all pathways considered consistently outperforms the other metals. We note that the most promising materials closely match the optimal candidates found by the energetic activity-descriptor analysis. However, the exchange kinetics suggests contrary to the energetic activity-descriptor analysis that the carbon adsorption energy of the optimal materials closely matches the optimum. Thus in the exchange activity analysis, the competition between carbon coverage and the lowering of the methane activation barrier moves the volcano peak toward weaker C-binding regimes. A comparison of Fig. 3 and 4 reveals that the predicted reaction steps ascribed to the regimes of lowest activity are heavily influenced by the chosen approach for describing the activity. For instance, for the $\mathrm{C}+\mathrm{O}$ pathway on stepped surfaces, the energetic analysis finds that in the regime of weak carbon and oxygen binding strengths the first dehydrogenation step limits the activity. The CO formation step becomes limiting for strong carbon and oxygen binding regimes. In contrast, the dehydrogenation step in the kinetic analysis is strongly inhibited by lack of free sites in the regime of strong carbon and oxygen binding affinities, while the increasing reaction barrier for both the $\mathrm{CO}$ formation and dehydrogenation step for lower oxygen and carbon binding strengths influences the $\mathrm{CO}$ formation step the most, as this step contrary to the dehydrogenation step benefits from an increased coverage. This emphasizes the importance of including the effects of the coverages in the analysis.

The hydrogen oxidation kinetics is strongly influenced by the pressure conditions; ${ }^{45}$ likewise pressure conditions also influence the kinetics of the methane oxidation. In Fig. 5 we see the changes in the optimum position when the pressure of $\mathrm{CH}_{4}, \mathrm{CO}_{2}$, and $\mathrm{H}_{2}$ changed from standard conditions to $1 \mathrm{mbar}$ each. The pressure of
$\mathrm{H}_{2} \mathrm{O}$ has the largest impact, where the optimum is moved $0.5 \mathrm{eV}$ and peaks close to $\mathrm{Co}$, while the impact of $\mathrm{CH}_{4}$ and $\mathrm{CO}_{2}$ is less pronounced. A reduction in the pressures of the product gases favors materials that bind oxygen stronger than $\mathrm{Co}$ and $\mathrm{Fe}$; however, these materials tend to oxidize and thus may not be strong candidates under fuel cell operation conditions.

Over the terraces, the hypothetical optimal catalyst is less active than it would be over the steps, and the catalyst materials need to bind carbon slightly stronger to reach the optimum. The stronger carbon binding of the undercoordinated surfaces aids the methane activation, and these turn out to be more active and actually reach the peak of the volcano.

A closer inspection of the rates of the dominant reaction candidates ( $\mathrm{Ni}, \mathrm{Ru}, \mathrm{Rh}, \mathrm{Ir}, \mathrm{Pd}$, and $\mathrm{Pt}$ ) reveals the $\mathrm{CH}+\mathrm{O}$ mechanism to be the more dominant mechanism on the terrace. However, the rates at the terraces are typically 2 orders of magnitude slower than the rates for the $\mathrm{C}+\mathrm{O}$ mechanism that is the dominant mechanism on the undercoordinated surfaces. This suggests that the steps determine the total reaction rate. However, one has to bear in mind that terrace sites typically are an order of magnitude more abundant than the step sites for larger nanoparticles, ${ }_{55}^{5}$ and step sites could be poisoned by trace amounts of sulfur. ${ }^{56}$

\section{Discussion}

We have summarized the methane oxidation process in terms of simple descriptors and furthermore investigated different reaction pathways. For all considered models and surfaces, $\mathrm{Ru}, \mathrm{Ni}, \mathrm{Rh}$, and Co consistently appear to be strong SOFC anode candidates. In particular, $\mathrm{Ru}$ is at the very top of the volcano for all considered pathways and thus is very robust with respect to changes in the catalytic pathway. However, reducing the pressures of the gas-phase products moves the optimum toward materials that bind oxygen stronger than Co.

The analysis only depends on the carbon and oxygen adsorption 
potentials. It does not consider thermal stability, resistance toward contamination (coking, sulfurization, or oxidation), expansion coefficients, and price, which naturally may discard some of the considered materials.

The method only focuses on optimizing the elemental surface reactions, which proves a necessary but not necessarily sufficient condition for optimal performance. For instance, in the regime close to the peak of the volcano ( $\mathrm{Rh}, \mathrm{Ni}, \mathrm{Ru}$, and $\mathrm{Co}$ ), the surface processes might already be optimized compared to other possible ratelimiting processes in the SOFC such as charge-transfer processes or surface and bulk processes at the electrolyte. For hydrogen oxidation on $\mathrm{Ni}$ there is experimental evidence that charge-transfer processes are rate-limiting, ${ }^{45}$ and that the relevant process is the hydrogen spillover process. Hydrogen oxidation on $\mathrm{Pt}$ is found to follow the oxygen spillover mechanism. ${ }^{57}$ This is consistent with the trend description of the hydrogen oxidation reaction in Ref. 8 and 9, where the oxygen spillover surface processes of $\mathrm{Pt}$ and $\mathrm{Ni}$ are far from and close to optimal, respectively. The fact that the trend description agrees with the trend of experimental activities thus suggests that oxygen spillover processes at the anode certainly take an active role and thus need to be optimized.

As we only consider the exchange rate at zero overpotential and thus assume everything to be equilibrated, we do not consider effects of surface diffusion, which may lead to buildup of concentration gradients. ${ }^{44}$ Also an increased overpotential will, in our approach, essentially drive oxygen to the surface. So beyond the influence of diffusion processes, and that the kinetic models need to include several concurrent RDSs, the effect of oxygen-oxygen repulsion at higher coverages also needs to be addressed.

In our approach, methane is assumed to be electrochemically oxidized; however, methane is commonly assumed to be steamreformed with subsequent transport of hydrogen to the three-phase boundary which is then oxidized. ${ }^{27}$ Even though our assumption that methane is directly oxidized should prove wrong, the surface processes in the mechanism still need to be optimized.

Some evidence that the surface processes even close to the peak of the volcano are not fully optimized is given by a recent experimental observation of Hibinio et al. ${ }^{58}$ In their experiment, small additions of $\mathrm{Ru}$ to the $\mathrm{Ni}$ anode led to an unprecedented high anode activity of the SOFC for several different considered fuels (methane, ethane, and propane). Whether this is directly related to methane oxidation or if the addition of $\mathrm{Ru}$ instead enhances the steam reforming reaction which also is optimized for this material is debatable. However, it suggests that the activity due to elemental methane surface reactions can be most likely improved.

Thus, even though the trend description does not account for all of the possible scenarios taking place under the methane oxidation process, it is believed that it at least aids in optimizing the surface processes. The simple description, however crude it might appear, is also the strength of the analysis. It confirms that $\mathrm{Ni}$ is close to the top of the volcano and points to $\mathrm{Ru}, \mathrm{Rh}$, and $\mathrm{Co}$ as other active candidates. However, because the material essentially only needs to reproduce the carbon and oxygen binding strength of the model, it also allows us to search for materials that are more resistant toward sulfur poisoning or coking than $\mathrm{Ni}$ and less costly than, for instance, $\mathrm{Ru}, \mathrm{Rh}$, and Co. This can be done in terms of alloying, and simple linear interpolation schemes have already been applied ${ }^{54}$ to estimate the binding strengths on alloys.

\section{Conclusion}

We have investigated the high temperature electrochemical methane oxidation process from the perspective of "classical" heterogeneous catalysis. With extensive use of scaling relations for the reaction energetics, and BEP relations for the reaction barriers as well as appropriate thermodynamic corrections, we have analyzed the kinetics of methane oxidation in terms of the oxygen and carbon adsorption energies. This analysis can be represented as activity volcanoes, where we, at standard pressures, find $\mathrm{Ru}$ to be a near optimal catalyst. We have assumed an oxygen spillover pathway and only opti- mize surface reaction processes. This is a necessary but not sufficient analysis as at the peak of the volcano other processes may limit the rate. However, recent experimental evidence finds that Ni doped with small amounts of $\mathrm{Ru}$ enhances the activity for oxidation of higher carbohydrates. ${ }^{58}$ This suggests that the surface processes are not fully optimized even close to the peak of the volcanoes.

Finally, the presented analysis suggests that the reaction preferentially takes place at undercoordinated sites. For the reaction to take place at close-packed surfaces the $\mathrm{CO}$ formation can only be accomplished through the formation of a $\mathrm{HCO}$ intermediate.

\section{Acknowledgments}

The Center for Atomic-scale Materials Design is funded by the Lundbeck Foundation. This work was supported by the Danish National Advanced Technology Foundation. The calculations were performed with the help from the Danish Center for Scientific Computing.

Technical University of Denmark assisted in meeting the publication costs of this article.

\section{References}

1. S. C. Singhal and K. Kendall, High Temperature Solid Oxide Fuel Cells: Fundamentals, Design and Applications, Elsevier, New York (2003).

2. J. H. Wang and M. Liu, Electrochem. Commun., 9, 2212 (2007).

3. J. B. Hansen, Electrochem. Solid-State Lett., 11, B178 (2008).

4. N. M. Galea, E. S. Kadantsev, and T. Ziegler, J. Catal., 111, 14457 (2007).

5. R. Rosei, F. Ciccacci, R. Memeo, C. Mariani, L. S. Caputi, and L. Papagno, J. Catal., 83, 19 (1983).

6. Y. Gamo, A. Nagashima, M. Wakabayashi, M. Terai, and C. Oshima, Surf. Sci., 374, 61 (1997).

7. S. Helveg, C. López-Cartes, J. Sehested, P. L. Hansen, B. S. Clausen, J. R. RostrupNielsen, F. Abild-Pedersen, and J. K. Nørskov, Nature (London), 427, 426 (2004).

8. J. Rossmeisl and W. G. Bessler, Solid State Ionics, 178, 1694 (2008).

9. J. Mukherjee and S. Linic, J. Electrochem. Soc., 154, B919 (2007).

10. M. P. Andersson, F. Abild-Pedersen, I. Remediakis, T. Bligaard, G. Jones, J. Engbæk, O. Lytken, S. Horch, J. H. Nielsen, J. Sehested, et al., J. Catal., 255, 6 (2008).

11. O. R. Inderwildi, S. J. Jenkins, and D. A. King, Angew. Chem., Int. Ed., 47, 5253 (2008).

12. F. Abild-Pedersen, J. Greeley, F. Studt, J. Rossmeisl, T. R. Munter, P. G. Moses, E. Skúlason, T. Bligaard, and J. K. Nørskov, Phys. Rev. Lett., 99, 016105 (2007).

13. J. K. Nørskov, T. Bligaard, A. Logadottir, S. Bahn, L. B. Hansen, M. Bollinger, H. Bengaard, B. Hammer, Z. Sljivancanin, M. Mavrikakis, et al., J. Catal., 210, 275 (2002).

14. T. Bligaard, J. K. Nørskov, S. Dahl, J. Matthiesen, C. H. Christensen, and J. Sehested, J. Catal., 224, 206 (2004)

15. T. Bligaard, V. Petzold, V. Tripkovic, E. Skulason, P. G. Moses, E. M. Fernandez, G. Jones, J. Kleis, F. Abild-Pedersen, J. K. Nørskov, et al., Unpublished work.

16. M. C. Payne, M. P. Teter, D. C. Allan, T. A. Arias, and J. D. Joannopoulos, Rev Mod. Phys., 64, 1045 (1992).

17. B. Hammer, L. B. Hansen, and J. K. Nørskov, Phys. Rev. B, 46, 7413 (1999).

18. M. Boudart, Adv. Catal., 20, 153 (1969).

19. G. A. Somorjai, Introduction to Surface Science and Catalysis, John Wiley \& Sons, New York (1994)

20. C. J. H. Jacobsen, S. Dahl, P. L. Hansen, E. Törnqvist, H. Topsøe, D. V. Prip, P. B. Møenshaug, and I. Chorkendorff, J. Mol. Catal. A: Chem., 163, 19 (2000).

21. J. K. Nørskov, T. Bligaard, B. Hvolbæk, F. Abild-Pedersen, I. Chorkendorff, and C. H. Christensen, Chem. Soc. Rev., 37, 2163 (2008).

22. R. A. van Santen, Acc. Chem. Res., 42, 57 (2009).

23. D. Vanderbilt, Phys. Rev. B, 41, 7892 (1990).

24. An open source code available at https://wiki.fysik.dtu.dk/ase, last accessed Oct 5, 2009.

25. G. Mills, H. Jónsson, and G. K. Schenter, Surf. Sci., 324, 305 (1995).

26. F. Abild-Pedersen, Ph.D. Thesis, Technical University of Denmark, Kgs. Lyngby, Denmark (2005).

27. E. S. Hecht, G. K. Gupta, H. Zhu, A. M. Dean, R. J. Kee, L. Maier, and O. Deutschmann, Appl. Catal., A, 295, 40 (2005).

28. G. Jones, T. Bligaard, F. Abild-Pedersen, and J. K. Nørskov, J. Phys.: Condens. Matter, 20, 064239 (2008).

29. P. W. Atkins, Physical Chemistry, 6th ed., pp. 485, 925-927, and 942, Oxford University Press, Oxford (1998).

30. CRC Handbook of Chemistry and Physics, 49th ed., R. C. Weast, Editor, p. D109, The Chemical Rubber Company, Cleveland, OH (1968).

31. J. H. Noogle, Physical Chemistry, Little, Brown, and Co., Boston, MA (1985)

32. E. V. Tsipis and V. V. Kharton, J. Solid State Electrochem., 12, 1367 (2008).

33. V. M. Janardhanan and O. Deutschmann, Z. Phys. Chem., 221, 443 (2007).

34. S. P. Jiang and S. H. Chan, J. Mater. Sci., 39, 4405 (2004).

35. V. N. Chebotin, M. V. Glumov, A. D. Neuimin, and S. F. Palguev, Sov. Electrochem., 7, 55 (1971).

36. P. Holtappels, I. C. Vinke, L. G. J. de Haart, and U. Stimming, J. Electrochem Soc., 146, 2976 (1999). 
37. S. Primdahl and M. Mogensen, J. Electrochem. Soc., 144, 3409 (1997).

38. B. de Boer, Ph.D. Thesis, University of Twente, Twente, The Netherlands (1998).

39. M. Mogensen and T. Lindegaard, in Proceedings of the Third International Symposium on Solid Oxide Fuel Cells, S. C. Singhal and H. Iwahara, Editors, PV 93-4, p. 484, The Electrochemical Society Proceedings Series, Pennington, NJ (1993).

40. W. G. Bessler, Solid State Ionics, 176, 997 (2005).

41. A. Bieberle and L. J. Gauckler, Solid State Ionics, 146, 23 (2002).

42. A. S. Ioselevich and A. A. Kornyshev, Fuel Cells, 1, 40 (2001).

43. J. Mizusaki, H. Tagawa, T. Saito, T. Yamamura, K. Kamitani, K. Hirano, S. Ehara, T. Takagi, T. Hikita, M. Ippommatsu, et al., Solid State Ionics, 70, 52 (1994).

44. M. Vogler, A. Bieberle-Hütter, L. Gauckler, J. Warnatz, and W. G. Bessler, J. Electrochem. Soc., 156, B663 (2009).

45. W. G. Bessler, J. Warnatz, and D. G. Goodwin, Solid State Ionics, 177, 3371 (2007).

46. A. Atkinson, S. Barnett, R. J. Gorte, J. T. S. Irvine, A. J. McEvoy, M. Mogensen, S. C. Singhal, and J. M. Vohs, Nature Mater, 3, 17 (2004).

47. J. Zhu, J. G. van Ommen, A. Knoester, and L. Lefferts, J. Catal., 230, 291 (2005).

48. Y. Hao and D. G. Goodwin, J. Electrochem. Soc., 155, B666 (2008).

49. V. M. Janardhanan and O. Deutschmann, J. Power Sources, 162, 1192 (2006).
50. G. Jones, J. G. Jakobsen, S. S. Shim, J. Kleis, M. P. Andersson, J. Rossmeisl, F. Abild-Pedersen, T. Bligaard, S. Helveg, B. Hinnemann, et al., J. Catal., 259, 147 (2008).

51. P. Ferrin, A. U. Nilekar, J. Greeley, M. Mavrikakis, and J. Rossmeisl, Surf. Sci., 602, 3424 (2008).

52. J. Cheng and P. Hu, J. Am. Chem. Soc., 130, 10868 (2008).

53. J. K. Nørskov, T. Bligaard, J. Rossmeisl, and C. H. Christensen, Nat. Chem., 1, 37 (2009).

54. M. P. Andersson, T. Bligaard, A. Kustov, K. E. Larsen, J. Greeley, T. Johannessen, C. H. Christensen, and J. K. Nørskov, J. Catal., 239, 501 (2006).

55. B. Hammer, O. H. Nielsen, and J. K. Nørskov, Catal. Lett., 46, 31 (1997).

56. H. S. Bengaard, J. K. Nørskov, J. Sehested, B. S. Clausen, L. P. Nielsen, A. M. Molenbroek, and J. R. Rostrup-Nielsen, J. Catal., 209, 365 (2002).

57. B. Luerssen, S. Günther, H. Marbach, M. Kisikinova, J. Janek, and R. Imbihl, Chem. Phys. Lett., 316, 331 (2000).

58. T. Hibino, A. Hashimoto, M. Yano, M. Suzuki, and M. Sano, Electrochim. Acta, 48, 2531 (2003)

59. See EPAPS supplementary material at http://dx.doi.org/10.1149/1.3230622 (EJESOAN-156-007912) for additional information. 